\title{
Análise microbiológica da água de coco comercializada por ambulantes na cidade de Volta Redonda - RJ
}

\section{Rosângela Duarte}

Nutricionista, Centro Universitário de Volta Redonda - UniFOA, Campus Olezio Galotti - Avenida Paulo Erlei Alves Abrantes, 1325, Três Poços, Volta Redonda, RJ, Cep 27240-560, telefone (24) 3340-8400.

E-mail: rosangeladuarte1973@gmail.com

\begin{abstract}
Aline Cristina Teixeira Mallet
Doutora em Ciência dos Alimentos, Centro Universitário de Volta Redonda UniFOA, Campus Olezio Galotti - Avenida Paulo Erlei Alves Abrantes, 1325, Três Poços, Volta Redonda, RJ, Cep 27240-560.
\end{abstract}




\section{Resumo}

A comercialização da água de coco por ambulantes cresce significativamente como forma de uma renda extra. Com a finalidade de impedir a contaminação do alimento a ser comercializado, estudos evidenciam que, para o manuseio do coco, o manipulador precisa estar capacitado em condutas de boas práticas sanitárias. Diante disso, o estudo teve como objetivo avaliar a qualidade microbiológica de água de coco comercializada por ambulantes do município de Volta Redonda, RJ. As análises foram realizadas durante os meses de julho e agosto de 2016. Realizaram-se em laboratório análises para coliformes totais e coliformes a $45^{\circ} \mathrm{C}$, Salmonella spp. e $\mathrm{pH}$. Para contagem de coliforme, utilizou-se a técnica do número mais provável (NMP). Amostras analisadas confirmaram presença de coliformes termotolerantes, estando em desacordo com as normas sanitárias determinadas pela legislação vigente, necessitando-se a adoção de medidas que previnam a contaminação do fruto.

Palavras-chave: Água de coco. Contaminação. Microbiológica.

\section{Abstract}

The commercialization of coconut water by street vendors has grown significantly as a form of extra income. In order to prevent the contamination of the food to be commercialized, studies show that for the handling of the coconut the manipulator must be trained in good sanitary practices. Therefore, the study aimed to evaluate the microbiological quality of coconut water marketed by street vendors in the city of Volta Redonda, RJ. The analyzes were carried out during the months of July and August of 2016. He carried out laboratory analyzes for total coliforms and coliforms at $45{ }^{\circ} \mathrm{C}$, Salmonella spp. And pH. The most probable number technique (MPN) was used for coliform counting. Samples analyzed confirmed the presence of thermotolerant coliforms, being in disagreement with the sanitary norms determined by the current legislation, making it necessary to adopt measures to prevent the contamination of the fruit.

Keywords: Coconut water. Contamination. Microbiological. 


\section{Introdução}

O coqueiro (Cocus nucifera L.) é de origem asiática e foi introduzido no Brasil no século XV. Presente na cavidade da semente do coco, a água de coco é uma solução naturalmente rica em sais minerais, vitaminas e proteína, constituída de água e 5\% de açúcar (VALVERDE; BADARÓ, 2009).

O consumo da água de coco cresce significativamente, principalmente no comércio informal como forma de uma renda extra. Essa circunstância pode ter sido imposta pelos meios de comunicações, com a disseminação sobre as vantagens que água de coco proporciona para a saúde. Entretanto, deve-se evidenciar que, para a manipulação do coco, o vendedor precisa estar capacitado em condutas de boas práticas sanitárias, com a finalidade de impedir a contaminação do alimento a ser comercializado (RIOS; SOBRINHO, 2012).

Embora esteja livre de contaminação enquanto na sua proteção natural, a água de coco, por dispor uma composição rica em nutrientes que favorecem a um rápido crescimento microbiano após a abertura do fruto, caso entre em contato com ambiente e equipamentos contaminados durante a extração, pode incorporar microrganismos ao seu conteúdo interno. Outra preocupação é a qualidade do gelo que se utiliza dentro do reservatório térmico para refrigeração dos frutos que pode contaminar o produto. São vários microrganismos que conseguem infectar o coco externamente, como as bactérias patogênicas Escherichia coli, Staphylococcus aureus, Salmonella, Bacillus cereus, Clostridium botulinum, entre outros (FROEHLICH, 2015).

A transmissão de microrganismo inicial da água de coco pode estar relacionada ao avariar o envoltório do fruto na hora da colheita e do transporte. O que confirma a total importância das providências profiláticas do coco antes da retirada do seu líquido, fazer uso das boas práticas durante toda sua metodologia, para que não haja contaminações resultantes de aparatos e de indivíduos implicados no processo (ABREU, 2005; RIOS; SOBRINHO, 2012).

O Ministério da Agricultura, Pecuária e Abastecimento, por meio da Instrução Normativa no 27 de 22 de julho de 2009, aprovou o regulamento técnico para a fixação do padrão de qualidade e identidade da água de coco. Define-a como bebida obtida da parte líquida do fruto de coqueiro, por meio de processo tecnológico adequado não diluído e não fermentado: água de coco "in natura" - não pode ser submetida a nenhum 
processo físico ou químico e que se destine para ingestão logo após sua extração (BRASIL, 2009).

A Agência Nacional de Vigilância Sanitária (ANVISA) adota como padrão de qualidade microbiológico a resolução RDC no 12/2001, a qual apresenta como parâmetros para a água de coco uma tolerância máxima de $10^{2}$ de coliformes a $45^{\circ} \mathrm{C}$ e ausência de Salmonella spp./25ml (BRASIL, 2001).

Assim, diante do exposto, o objetivo do presente estudo foi avaliar a qualidade microbiológica de água de coco comercializada por ambulantes do município de Volta Redonda, RJ.

\section{Materiais e Métodos}

\section{OBTENÇÃO DAS AMOSTRAS}

As análises foram realizadas durante os meses de julho e agosto de 2016. Para tal, foram selecionadas nove amostras de água de coco in natura, em garrafas descartáveis de $450 \mathrm{ml}$, adquiridas diretamente dos ambulantes, em nove pontos de comercialização na cidade de Volta Redonda, RJ. As mesmas foram imediatamente colocadas em bolsa térmica, contendo gelo e levadas ao laboratório de Microbiologia de Alimentos do Centro Universitário de Volta Redonda (UniFOA), para as devidas análises. Foram realizadas análises para coliformes a $45^{\circ} \mathrm{C}$, Salmonella spp. e pH. Os resultados das análises microbiológicas foram comparados com os valores estabelecidos pela Legislação Brasileira Vigente, regida pela RDC N 12, 02 de janeiro de 2001 da Agência Nacional de Vigilância Sanitária - ANVISA.

\section{DETERMINAÇÃO DE COLIFORMES A 45C E TERMOTOLERANTES}

Para contagem de coliformes a $45^{\circ} \mathrm{C}$ e termotolerantes, utilizou-se a técnica do número mais provável (NMP), empregando três séries de três tubos. $\mathrm{O}$ teste presuntivo foi constituído pela homogeneização de $1 \mathrm{ml}$ de cada amostra em $9 \mathrm{ml}$ de água peptonada (0,1\%). Em seguida, foram realizadas diluições seriadas em água peptonada a 
0,1\%. Alíquotas de $1 \mathrm{ml}$ das diluições apropriadas foram semeadas em caldo lauril sulfato triptose e incubadas a $45^{\circ} \mathrm{C}$ por $24-48$ horas. Após esse período, os tubos positivos, com apresentação de gás e turvação, foram transferidos para tubos contendo caldo verde brilhante (VB) e incubados a $45^{\circ} \mathrm{C}$ por $24-48$ horas, constituindo-se essa etapa no teste confirmativo dos tubos positivos. Para o teste presuntivo, alíquotas de cultura dos tubos positivos em caldo VB foram transferidas com auxílio de alça de níquel cromo para tubos contendo caldo Escherichia coli (EC), as quais foram incubadas a $45^{\circ} \mathrm{C}$ por $24-48$ horas, constituindo o teste para a determinação do NMP de coliformes termotolerantes presentes na amostra (SILVA, 2007).

Os resultados foram analisados de acordo com as diluições e a quantidade de amostras positivas do teste confirmativo, orientando-se pelo uso da tabela de NMP da Bacteriological Analytical Handbook.

\section{SALMONELLA SPP.}

Retirou-se assepticamente uma porção de $25 \mathrm{ml}$ da amostra, adicionando-a em $225 \mathrm{~mL}$ de água peptonada tamponada. Posteriormente, a amostra foi incubada a $37^{\circ} \mathrm{C}$ por 24 horas (fase de pré-enriquecimento). Na sequência, realizou-se a etapa do enriquecimento seletivo em que foi transferido $0,1 \mathrm{~mL}$ desta diluição, para um tubo de ensaio contendo $10 \mathrm{ml}$ de Caldo Tetrationato, incubando a $37^{\circ} \mathrm{C}$ por 24 horas e $1 \mathrm{ml}$ transferido para um tubo contendo Caldo Rapapport, incubando a $37^{\circ} \mathrm{C}$ por 24 horas. A partir dos tubos dos caldos anteriores, foi retirada uma alçada de cada um dos préenriquecimentos e inoculada em duas placas de Petri, contendo os meios SalmonellaShigella (SS) e Hecktoen entérico (He). Estas foram incubadas a $37^{\circ} \mathrm{C}$ por 24 horas (SILVA, 2007)

\section{DETERMINAÇÃO DO pH}

$\mathrm{O} \mathrm{pH}$ foi determinado por meio do Papel Indicador de $\mathrm{pH}$ (0-14) Merck, embalagem caixa c/ 100 (cem) tiras, utilizado para a verificação direta do valor do $\mathrm{pH}$ em soluções aquosas, nos laboratórios para controle de qualidade. O método do teste é a escala colorimétrica e o tempo de resposta: 1-10 minutos. 


\section{Resultados e Discussão}

Dentre nove amostras analisadas, verificou-se que 33\% (3) apresentaram teste confirmativo positivo para coliformes totais e termotolerantes estando em desacordo com a Legislação Federal vigente a qual estabelece limite máximo de $10^{2} \mathrm{UFC} / \mathrm{ml}$ (BRASIL, 2001) apenas uma amostra (11,1\%) apresentou resultado positivo quanto à presença de Salmonella spp. (Tabela1).

Tabela 1. Resultados obtidos na análise microbiológica da água de coco comercializada por ambulantes na Cidade de Volta Redonda (RJ)

\begin{tabular}{|cccl} 
Amostra & $\begin{array}{c}\text { Coliformes Totais } \\
(\mathrm{UFC} / \mathrm{mL})\end{array}$ & $\begin{array}{c}\text { Coliformes Termotolerantes } \\
(\mathrm{UFC} / \mathrm{mL})\end{array}$ & Salmonella \\
\hline CA1 & 4 & 7 & Ausentes \\
\hline CA2 & 7 & 7 & Ausentes \\
\hline CA3 & 0 & 0 & Ausentes \\
\hline CA4 & $1,2 \times 10^{2}$ & $1,2 \times 10^{2}$ & Ausentes \\
\hline CA5 & 9 & $2,1 \times 10^{1}$ & Ausentes \\
\hline CA6 & $4,6 \times 10^{2}$ & $4,6 \times 10^{2}$ & Ausentes \\
\hline CA7 & $2,4 \times 10^{2}$ & $2,4 \times 10^{2}$ & Ausentes \\
\hline CA8 & 0 & 0 & Ausentes \\
\hline CA9 & $2,3 \times 10^{1}$ & $4,3 \times 10^{1}$ & Presente \\
\hline
\end{tabular}

Valor máximo preconizado pela legislação vigente: $10^{2} \mathrm{UFC} / \mathrm{mL}$ (coliforme termotolerantes) e ausência em $25 \mathrm{~g} / 25 \mathrm{ml}$ para Salmonella spp. Fonte: Autora

Segundo MACEDO (2015), a presença de coliformes totais em amostras pode não ser indício de contaminação por fezes ou ocorrência de enteropatógenos. Já a presença de coliformes termotolerantes (à $45^{\circ} \mathrm{C}$ ) é um indicativo, com maior segurança, informando sobre a condição higiênica da matéria prima, equipamento sujo ou manipulação sem cuidados higiênicos, colocando em risco a qualidade microbiológica da água de coco vendida por ambulantes.

Para SILVA et al. (2010, o aparecimento de coliformes totais em amostras de coco aponta uma higienização inadequada, já que, ao haver contato com o solo, o fruto deve ser sanificado, com intuito de remover e/ou diminuir resíduos e complicações 
associadas com a infecção microbiana originária do solo, ou inexistência de boas práticas de higiene.

Encontram-se na literatura diversos estudos que apresentam resultados confirmados para contaminação microbiológica da água de coco vendida por ambulantes em distintas cidades no Brasil, como é demonstrado por FORTUNA e FORTUNA (2008) que, ao avaliaram a qualidade microbiológica de 32 (trinta e duas) amostras de água de coco comercializadas em carrinhos de ambulantes na cidade de Teixeira de Freitas (BA), verificaram que em 11 (onze) (34,4\%) das amostras constatou-se a presença de coliformes à $45^{\circ} \mathrm{C}$, com valores acima do permitido. Resultados semelhantes foram relatados por Valverde e Badaró (2009) já que das 25 (vinte e cinco) amostras de água de coco analisadas, 24 (vinte e quatro) (96\%) encontravam-se fora dos limites estabelecidos quanto à presença de coliformes termotolerantes, demonstrando procedimento falho na higienização durante a manipulação, já que a presença desse grupo de microrganismos em alimentos prontos para o consumo é um importante indicador de contaminação após o processamento.

AMALDAS et al. (2009) em estudo sobre qualidade microbiológica de água de coco comercializadas no município de Currais Novos/RN verificaram que 5 (cinco) amostras (23\%), das 22 (vinte e duas) analisadas, apresentaram resultados insatisfatórios para contagem de coliformes termotolerantes e 18 (dezoito) (82\%) para coliformes totais. Esses resultados são similares ao encontrados por ALBUQUERQUE et al. (2011), que avaliaram 16 (dezesseis) amostras de água de coco comercializadas no centro da cidade de Fortaleza/CE e constataram que 87\%, 14 (quatorze) das mesmas ultrapassaram as especificações da Agência Nacional de Vigilância Sanitária (ANVISA) quanto a presença de coliformes a $45^{\circ} \mathrm{C}$.

Outro estudo conduzido na cidade de Campos dos Goytacazes/RJ por SANTOS et al. (2012) ao realizaram a pesquisa, constataram que das 9 (nove) amostras analisadas, 5 (cinco) 55\% pertenciam ao grupo dos Coliformes termotolerantes.

Diversos trabalhos apresentados até o momento corroboram com os resultados encontrados pelo presente estudo, e evidenciam a importância que a higienização adequada dos frutos e utensílios, bem como as boas práticas de manipulação são de extrema relevância para a comercialização deste produto.

A pesquisa realizada por CARVALHO et al. (2012) na cidade de Itabuna, Bahia, apresentou resultados bem expressivos como os anteriores. As águas de coco 
foram coletadas em 18 (dezoito) pontos de venda distintos. Destas, 9 (nove) 55\% apresentaram-se contaminadas com coliformes totais e 4 (quatro) 22\%, acima do estabelecido para coliformes termotolerantes.

Em 2013, SANTOS et al. avaliaram a qualidade microbiológica da água de coco vendida em Juazeiro do Norte/CE por ambulantes, também identificaram que a presença de coliforme a $45^{\circ} \mathrm{C}$ em $2(33 \%)$ das 6 (seis) amostras examinadas.

Tais dados reafirmam o que RIBEIRO e MARANGON (2011) relataram em seu estudo sobre a comercialização de água de coco em carrinhos ambulantes em Brasília (DF): a falta de condições para lavar as mãos e os utensílios, local inadequado para armazenamento e conservação do produto tornam falho todo o processo de manuseio para se obter um alimento que seja saudável para o consumo. No gráfico abaixo se encontra um compilado de estudos referente à contaminação de microrganismos em diferentes cidades brasileiras.

Gráfico 1. Estudos que apresentam resultados positivos para contaminação microbiológica da água de coco vendida por ambulantes em distintas cidades no Brasil

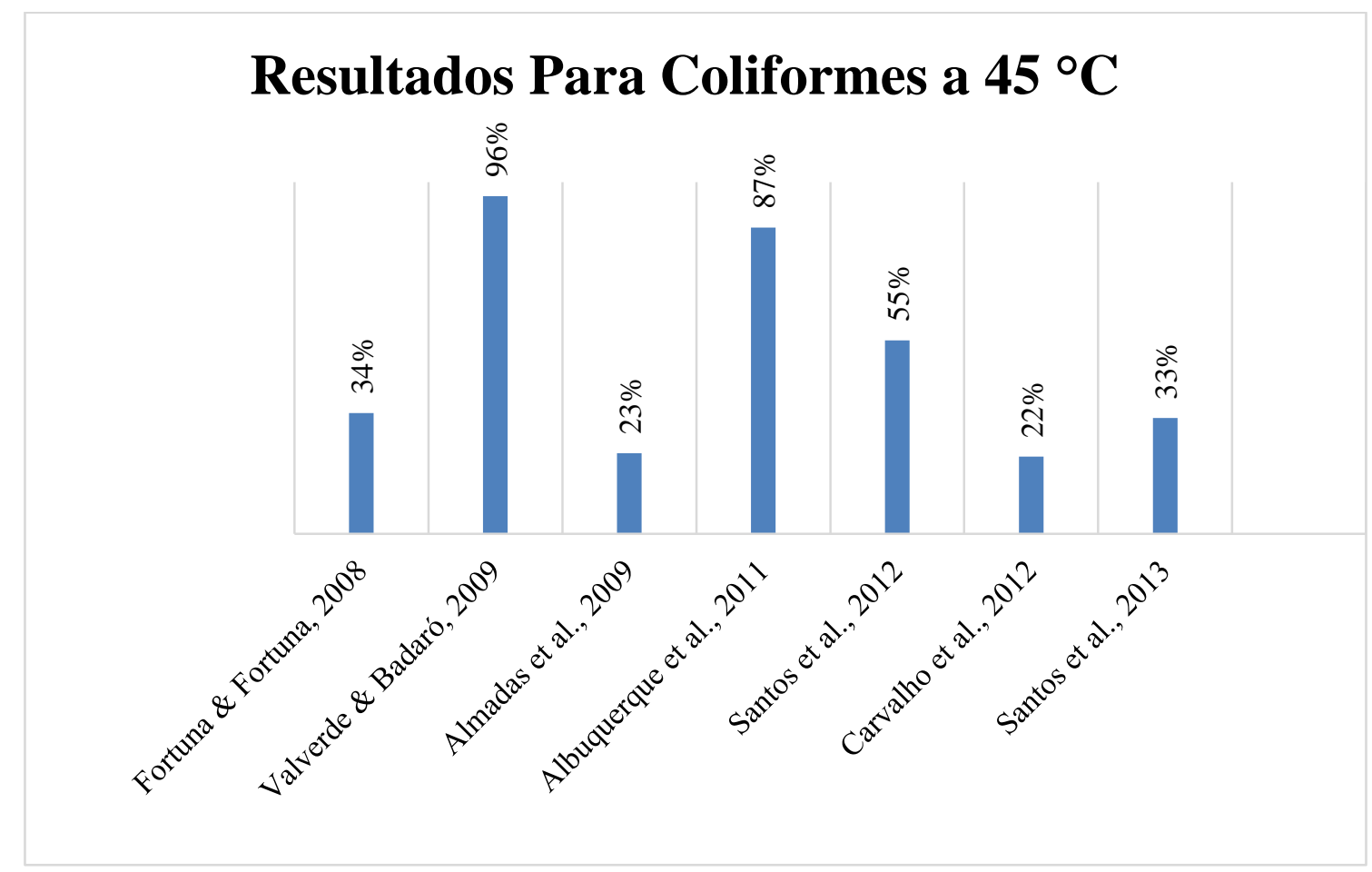

Fonte: Autora

A Salmonella é um dos microrganismos mais frequentemente envolvidos em casos e surtos de doenças de origem alimentar em diversos países, inclusive no Brasil. 
Sua epidemiologia indica que é amplamente distribuída na natureza, sendo o trato intestinal do homem e de animais o principal reservatório natural. Vários casos conhecidos de toxinfecção alimentar causadas por Salmonella são relatados, os quais envolvem tipos variados de alimentos (FRANCO; LANDGRAF, 2008).

$\mathrm{Na}$ presente pesquisa, das 9 (nove) amostras analisadas, 1(uma) (11,1\%) acusou a presença de Salmonella. A legislação em vigor, RDC no 12 de 2001, estabelece como padrão a ausência da mesma em $25 \mathrm{ml}$ do produto (Tabela 1 ). $\mathrm{O}$ fato de ter sido constatado na amostra a presença de Salmonella reforça a preocupação com a saúde do consumidor e evidencia que a comercialização da água de coco por ambulantes, além de precária, pode ser prejudicial à saúde daqueles que consomem este tipo de bebida (BOANOVA, 2014).

Diferentemente, ALMADAS et al. (2009) não constataram presença de Salmonella spp. em nenhuma das 22(vinte e duas) (100\%) amostras de água de coco. Tais resultados corroboram com os de CARVALHO et al. (2012) os quais evidenciaram a ausência para esse microrganismo em 100\% de suas amostras estudas.

Um dos vestígios para presença dessa bactéria na água de coco de acordo com FORTUNA e FORTUNA (2008) e DIAS et al. (2015), pode ser o resultado do contato do fruto com a terra contaminada, de seres vivos com capacidade para transmitir parasitas, tipo de transporte inadequado e local impróprio utilizados para estocagem dos cocos.

SANTOS et al. (2013) confirmaram que das 6 (seis) amostras de água de coco analisadas para Salmonella spp. não evidenciaram a presença desse microrganismo. Resultados similares foi apresentado por MENEZES et al. (2013) e DIAS et al. (2015) para 100\% das suas amostras estudadas, encontrando desta forma em conformidade com os padrões determinados pela legislação vigente (BRASIL, 2001).

Em relação às análises de $\mathrm{pH}$, foi observado que todas as amostras (100\%) apresentaram valores iguais a 5 (cinco), encontrando-se de acordo com Instrução Normativa $\mathrm{n}^{\mathrm{o}}$ 31, de 13 de agosto de 2009 (BRASIL, 2009), a qual estabelece pH mínimo de 4,3 (quatro, três) para água de coco.

De acordo com dados disponíveis na literatura científica, o $\mathrm{pH}$ da água de coco apresenta variação de acordo com a idade do fruto, sendo que, quando chega com idade de 5 (cinco) meses, encontra-se em torno de 4,7(quatro, sete) a 4,8 (quatro, oito), 
elevando-se acima de 5 (cinco) até o final do crescimento do fruto (ARAGÃO et al., 2001; CARVALHO et al., 2006).

Para FROEHLICH (2015), as características de baixa acidez da água de coco $(\mathrm{pH}>4,5)$, aliada ao seu crescente consumo, torna o produto nocivo para saúde da população. As 32 (trina e duas) amostras de água de coco analisadas por FORTUNA e FORTUNA (2008) apresentaram o pH em torno de 4,25 (quatro, vinte e cinco) e 6,30 (seis, trinta), e 14 (quatorze) (43,75\%) tiveram $\mathrm{pH}$ fora dos padrões.

A legislação brasileira não estabelece valores máximos para água de coco “in natura". Sua análise é significativa, pois o sabor doce e adstringência desejável são atingidos com $\mathrm{pH}$ próximos de 5,5 (cinco, cinco). E valores entre 4,8 (quatro, oito) e 5,0 (cinco) podem indicar problemas para o consumidor com crescimento de bactérias patogênicas que consegue multiplicar nessa faixa de $\mathrm{pH}$ (VASCONCELOS et al., 2015).

No presente estudo, o $\mathrm{pH}$ encontrado para as amostras de água de coco foi de 5 (cinco), isso explica a presença de microrganismo (MO) do tipo coliformes termotolerantes, que apesar de serem MO indicadores, são extremamente perigosos, e causam danos à saúde dos consumidores quando presentes nos alimentos e bebidas.

Os resultados para a presença de coliformes totais e termotolerantes evidenciam que as amostras de água de coco se encontram impróprias para o consumo humano. E, ao se pesquisar a carga microbiana e as condições salubres do produto, tornou-se possível descrever o estado do fruto, das pessoas envolvidas e principalmente da higienização inadequada dos equipamentos (SEREJO; NEVES; BRITO 2010).

\section{Conclusões}

Conclui-se que em algumas amostras analisadas evidenciou-se a presença de microrganismos, confirmando um risco potencial à saúde pública. A qualidade microbiológica da água de coco comercializada por ambulantes do município de Volta Redonda, RJ, encontra-se em desacordo com as normas sanitárias determinadas pela legislação vigente, RDC 12/2001 - ANVISA. Diante desta constatação, faz-se necessário a adoção de medidas que previnam a contaminação do fruto desde o transporte, armazenamento e manipulação até o consumidor final dessa bebida. 


\section{Referências}

ABREU, LF et al. Avaliação e adaptação de sistema asséptico para obtenção de água de coco (Cocos nucifera L.) acondicionada em embalagens plásticas, 2005. Biblioteca Digital da UNICAMP. Disponível em: <http://www.bibliotecadigital.unicamp.br>. Acesso em: 31 ago. 2016.

ALBUQUERQUE, Tiago L. de et al. Qualidade microbiológica da água de coco comercializada por ambulantes no centro de Fortaleza, CE. Hig. aliment, v. 25, n. 194/195, p. 30-34, 2011.

ALMADAS DA SILVA, Jonas Luiz Almada; DANTAS, Fabriny Aprígio Vieira; DA SILVA, Fábia Costa. Qualidade microbiológica de águas de coco comercializadas no município de Currais Novos/RN. Holos, v. 3, p. 34-41, 2009.

ARAGÃO, W. M.; ISBERNER, I. V.; CRUZ, E. M. O. Água de coco. Aracaju: Embrapa CPATC/Tabuleiros Costeiros. Documentos (INFOTECA-E), n. 24, p. 14, 2001. Disponível em: <http://www.infoteca.cnptia.embrapa.br/handle/doc/370873>. Acesso em: 21 out. 2016.

BOANOVA, Andréa Barbosa. Análise e Interpretação de denúncias sobre alimentos como ferramenta de gestão no município de São Paulo, 2014. Tese (Doutorado em Serviços de Saúde Pública) - Faculdade de Saúde Pública, Universidade de São Paulo, 2014. Disponível em: <http://bases.bireme.br>. Acesso em: 31 ago. 2016.

BRASIL. Agência Nacional de Vigilância sanitária (ANVISA). Resolução da Diretoria Colegiada (RDC) no 12, de 02 de janeiro de 2001. Disponível em:

<www.portal.anvisa.gov.br/RDC_12_2001>. Acesso em: 29 fev. 2016.

- Ministério da Agricultura, Pecuária e Abastecimento. Instrução

Normativa no 27. Diário Oficial da União. S. 1, p. 6, 2009. Disponível em: <www.imetro.gov.br>. Acesso em: 5 mar. 2016.

. Ministério da Agricultura, Pecuária e Abastecimento. Instrução

Normativa $n^{\circ}$ 31, S. 1, p. 32, 2009. Disponível em: <

http://extranet.agricultura.gov.br/sislegis-

consulta/consultarLegislacao.do?operacao=visualizar\&id=20667 >. Acesso em: 21 out. 2016. 
CARVALHO, Joelia Marques de et al. Água-de-coco: Propriedades nutricionais, funcionais e processamento. Semina ciênc. agrar, v. 27, n. 3, p. 437-452, 2006.

CARVALHO, L. R., PINHEIRO, B. E. C., PEREIRA, S. R., BORGES, M. A. S. F., \& de MAGALHÃES, J. T. Bactérias resistentes a antimicrobianos em amostras de água de coco comercializada em Itabuna, Bahia. Revista Baiana de Saúde Pública, v. 36, n. 3, p. 751- 763, 2012.

DA SILVA, Jonas Luiz Almada; DANTAS, Fabriny Aprígio Vieira; DA SILVA, Fábia Costa. Qualidade microbiológica de águas de coco comercializadas no município de Currais Novos/RN. Holos, v. 3, p. 34-41, 2010.

DA SILVA, Neusely et al. Manual de métodos de análise microbiológica de alimentos. São Paulo: Varela, 2007.

DIAS, F. M.; FIGUEIREDO, R. M.; SOUZA, J.R.; SANTANA, C.M.P. Qualidade Microbiológica da água de coco comercializada em carrinhos ambulantes, na região central do município de Vitória da Conquista, BA. Revista Brasileira de Produtos Agroindustriais. v.17, n.1, p.97-103, 2015.

DOS SANTOS, J. E. F. et al. Avaliação microbiológica de água de coco comercializada por ambulante em Juazeiro do Norte-CE. Revista Verde de Agroecologia e Desenvolvimento Sustentável, v. 8, n. 2, p. 23-26, 2013.

FORTUNA, D. B. S.; FORTUNA, J. L. Avaliação da qualidade microbiológica e higiênico-sanitária da água de coco comercializada em carrinhos ambulantes nos logradouros do município de Teixeira de Freitas (BA). Revista baiana de saúde pública, v. 32, n. 2, p. 203-2017, 2008.

FROEHLICH, Ângela. Água de Coco: Aspectos Nutricionais, Microbiológicos e de Conservação. Saúde e Pesquisa, v. 8, n. 1, p. 175-181, 2015.

LANDGRAF, M. Microrganismos Indicadores. In: FRANCO, B. D G. M.; LANDGRAF, M. Microbiologia dos alimentos, São Paulo: Atheneu. 2008.

MACEDO, Jamile Mariano; GOMES, Nicolas William Silva; ARAÚJO, Nilton Fagner Oliveira. Avaliação microbiológica da água de coco obtida por diferentes métodos de conservação no município de Porto Velho, Rondônia. South American Journal of Basic Education, Technical and Technological, v. 2, n. 2, 2015. 
MENEZES, E.A. et al. Avaliação da qualidade microbiológica de água de coco comercializada em Fortaleza, CE. Higiene alimentar, v. 27, n. 216/217, p. 113-118, 2013.

RIBEIRO, L. P.; MARANGON, A. F. Avaliação das condições de higiene dos carrinhos ambulantes de água de coco comercializada em Brasília-DF. Universitas: Ciências da Saúde. v. 9, n. 1, p. 1-12, 2011.

RIO, A.S.; SOBRINHO, R.S. Comercialização e Segurança Alimentar da Água De Coco Verde: Estudo Comparativo do Produtor e Vendedor. The 4th International Congress on University-Industry Cooperation. Taubate, SP. Brazil, 2012. Disponível em: <http://www.unitau.br/unindu/artigos/pdf549.pdf>. Acesso em: 05 mar. 2016.

SANTOS, VC et al. Avaliação da qualidade microbiológica da água de coco comercializada por ambulantes em Campos dos Goytacazes/RJ. Revista de Trabalhos Acadêmicos. n. 5, Jornada Científica. Brasil, 2012. Disponível em: <http://www.revista.universo.edu.br/index.php>. Acesso em: 31 ago. 2016.

SEREJO, M.T.T.; DAS NEVES, M.A.; BRITO, N.M. Qualidade Microbiológica da Água de coco (Cocos nucifera) comercializada por ambulantes da cidade de São Luís MA. In: V CONNEPI-2010. 2010.

VALVERDE, C. R.; BADARÓ, A. C. L. Qualidade microbiológica da água de coco (Cocus nucifera) comercializada por ambulantes na cidade de Ipatinga, Minas Gerais. Nutrir Gerais, v. 3, n. 5, p. 489-504, 2009.

VASCONCELOS, BMF et al. Qualidade físico-química da água de coco comercializada por ambulantes no município de Mossoró/RN. Blucher Chemistry Proceedings, v. 3, n. 1, p. 483-493, 2015. 